\title{
NURSE INTERRUPTED: DEVELOPMENT OF A REALISTIC MEDICATION ADMINISTRATION SIMULATION FOR UNDERGRADUATE NURSES.
}

\begin{abstract}
BACKGROUND: Medication errors are a global phenomenon. Each year Australia-wide there are up to 96,000 preventable medication errors and in the United States there are approximately 450,000 preventable medication errors. One of the leading causes of errors is interruption yet some interruptions are unavoidable. In the interest of patient safety, nurses need to not only understand the impact of interruptions, but also be empowered with the knowledge and skills required to develop effective interruption management strategies. Well-planned simulation experiences have the potential to expose students to authentic clinical cases, otherwise unavailable to them, building critical thinking and clinical reasoning skills and preparing them for practice.
\end{abstract}

AIM: This paper describes a simulated role-play experience that was developed to enable undergraduate nurses to experience, reflect on and analyse their responses to interruptions during medication administration.

METHODS: The simulation design presented in this paper was underpinned by both nursing and educational theorists, in combination with established simulation frameworks.

SETTING and PARTICIPANTS: Embedded within a clinical subject in 2013, the simulation experience was run over two campuses within a large Australian University. Participants included 528 second year undergraduate nursing students and 8 academic teaching staff.

OUTCOME MAPPING: To stimulate reflective learning debriefing immediately followed the simulation experience. Written reflections were completed and submitted over the 
following 4 weeks to extend the reflective learning process and review the impact of the experience from the student perspective.

CONCLUSIONS: Undergraduate student nurses often have limited experiential background from which to draw knowledge and develop sound clinical judgements. Through exposure to clinical experiences in a safe environment, simulation technologies have been shown to create positive learning experiences and improve deductive reasoning and analysis. The heightened awareness of interruptions and their impacts on the medication administration process, along with techniques to manage interruptions more effectively serves to better prepare nurses for practice. 


\section{INTRODUCTION/BACKGROUND}

Medication errors are a major threat to patient safety and remain a significant global health care issue (Clinical Excellence Commission \& Health 2013; Cloete 2015; Kohn, Corrigan \& Donaldson 2000). A leading cause of medication errors are interruptions and distractions during the medication administration (MA) process (Jennings, Sandelowski \& Mark 2011; Reid-Searl, Moxham \& Happell 2010). Nurses are primarily responsible for MA (Palese et al. 2009; Reid-Searl, Moxham \& Happell 2010), therefore, understanding how nurses learn the essential skills required to safely administer medications in spite of interruptions is crucial in achieving patient safety goals.

The clinical environment in which nurses find themselves is frequently unpredictable and there are unavoidable interruptions, including during MA (Westbrook et al. 2010). Safe and effective MA is a cornerstone of nursing practice and it is incumbent on nurses to be cognisant of the associated risks as well as the causes of medication errors (Page \& McKinney 2007).

Interruption reduction strategies have been the main focus of current research to prevent medication errors (Anthony et al. 2010; Flanders \& Clark 2010; Relihan et al. 2010). These strategies include the introduction of 'do not disturb' tabards or sashes, demarcated 'no go and quiet zones', ward signage, technology, and safety checklists (Anthony et al. 2010; Fore et al. 2013; Relihan et al. 2010). Although these initiatives are reported to have been successful in reducing interruptions, they are unable to eliminate them. Caution in utilizing these strategies as standalone measures has been suggested, until sufficient pre and post testing has been undertaken (Raban and Westbrook 2014). 
The inevitability of interruptions and distractions in the clinical environment, and the recognition that not all interruptions have negative outcomes is documented (Clark \& Flanders 2012; Flynn et al. 2012). There is little doubt that there is a direct relationship between the delivery of safe and effective patient care and the way in which nurses manage interruptions (Cloete 2015, Rochman et al. 2012). The traditional methods of teaching MA to undergraduate nurses include learning the relevant pharmacology and mathematics, and the six rights of MA (Woodrow, Colbert \& Smith 2010). Once availed of theoretical elements, students are then supervised practicing MA within a constructed, uninterrupted, clinical laboratory environment (Aggar \& Dawson 2014). Although these are all necessary steps in teaching novice nurses safe MA, translating skills learnt within the university setting, into the dynamic clinical environment can present students with significant challenges. Undergraduate nurses are often expected to learn interruption management strategies 'on the job', leaving both nurses and patients vulnerable. To contribute to more 'real life' experience of MA, innovative techniques such as role-play simulation that incorporate interruption management strategies are proposed.

\section{METHODS/PROTOCOL}

$\underline{\text { Aim }}$

This paper describes a simulated role-play experience that enables undergraduate nurses to experience, reflect on and analyse their responses to interruptions during medication administration. 


\section{Methodology}

The conceptual foundation for the design of this role-play drew on the work of both nursing and educational theorists including; Benner's novice to expert, Tanner's model of clinical judgement, and Kolb's theory of experiential learning (Benner 2001; Kolb 1984; Tanner 2006). It was further informed by Jeffries adaptation of Kolb's work as it applies to simulation in nursing (Jeffries 2005). The integration of these ideas is presented in diagram 1.

Benner described five stages of learning specific to nursing practice; novice, advanced beginner, competent, proficient and expert (Benner 2001). During the planning of this simulation role-play experience it was deemed that student participants were functioning within the first two stages, the novice and the advanced beginner.

Tanners' model (Tanner 2006) was utilised as a guide to ensure that student participants were given the opportunity to notice, interpret, respond to and reflect on their experience within a safe environment. Academic facilitators were encouraged to act as coaches guiding the learning experience, culminating in a planned debrief where students could make informed and reasoned judgements, incorporating appropriate prioritisation and optimal patient care choices.

The understanding that students vary in their preferred learning style and that concrete experiences lay the foundation for reflective observation was also considered (Kolb 1984). Therefore, following the simulation and debriefing, students were encouraged to complete written reflections to enhance transfer of the experience into abstract concepts, fostering an awareness of actions or responses to create new experiences and insights. 
Jeffries (2005) simulation framework was used to underpin the design, implementation and evaluation of the simulation, to facilitate and develop critical thinking and reasoning skills that lead to enhanced clinical judgement. Within the design of this experience all five elements of the Jeffries Simulation Framework were taken into consideration and are presented in table 2 . These approaches emphasise the impact of previous experiences on learning, and the ability to apply theory into practice through active involvement, problem solving, decision making, and reflection, leading to cognitive development and acquired knowledge (Howard et al. 2011).

\section{Setting and participant characteristics}

The simulation was instituted across two campuses of one large Australian University. Participants included a convenience sample of 528 second year undergraduate student nurses enrolled in a clinical subject in the Bachelor of Nursing program; male $(n=85)$ and female ( $n=443)$, with a mean age of 26.56 years. The cohort comprised a combination of direct entry, graduate entry, and enrolled nurse transition students. The second year of study was chosen as it is when students begin to consolidate MA skills. Casual and permanent academic teaching staff $(n=8)$ were directly involved in facilitating the simulation.

Design

Guiding students through the processes required to transfer theory into practice, is dependent on educators understanding the complex matrix involved in this progression. A valid framework was considered essential as the foundation for the design and content of this simulation to ensure that the simulation was of high quality and elicited maximum learning opportunities. A Delphi study involving contributions from national and 
international simulation experts, developed five evidenced based quality indicator statements, that when incorporated into simulation design and implementation provide high quality, effective teaching and learning experiences (Arthur, Levett-Jones \& Kable 2010). The outcomes of this consensus, the related statements produced, and how the study addressed those statements in the planning of the experience is outlined in table 1.

The most effective high fidelity simulations provide a realistic scenario and environment to encourage student immersion. Krautscheid et al. (2011) reviewed what students perceived as effective forms of MA education. They found that the students requested increased fidelity of experiences, incorporating learning how to manage interruptions and distractions.

Producing low cost, high fidelity simulation experiences can be a challenge. One approach to manage this issue is the utilisation of carefully planned role-play simulations where limited equipment is required. Literature specific to team training in the health care environment found that not only is role-play simulation cost effective, it also encourages maximum retention of new knowledge and skills through active participant involvement (Will \& Weinschreider 2012). Jenkins and Turick-Gibson (1999) identified high levels of active student participation, whereby feeling, thinking and acting in another person's place promoted learning using critical thinking skills.

Key to the success of this teaching strategy was enabling participants to make meaning of the experience through debriefing and reflection (Cant \& Cooper 2011; Jeffries 2005; Kolb 1984; Tanner 2006). Reflecting on practice encourages deep thinking (Kolb 1984). To that end students were encouraged to complete guided written reflective responses independent of the debriefing process. Guided reflections provide a depth of reflection, which is believed to increase the potential for clinical learning (Lasater 2009). A guide for 
reflection designed by Nielson, Stragnell and Jester (2007) was adapted to offer students some points for consideration including; how or if the interruptions affected concentration, identifying skills they had used to manage the situation, how or if they would approach the interruptions differently next time, and how or if the simulation prepared them for practice.

\section{Ethical Considerations}

The importance of maximising benefit for both the participants and the patients they care for in the future was paramount when designing this intervention. Exposure to the simulation afforded the student participants an opportunity to reflect on interruption management strategies that they will be able to call on in clinical practice. As the written reflections will be used as data to explore student perceptions of the experience, issues of power and autonomy including consent, participant privacy, emotional considerations and self-disclosure were considered. Participants were supplied with information sheets and given the opportunity to ask questions prior to the commencement of the simulation, ensuring informed consent. It was made clear that the written reflection was a noncompulsory exercise and that participation was voluntary. The right of eligible participants to exclude themselves from the experience was respected.

\section{Outcome mapping}

Each class group was observed to validate consistency of the experience, at which time some anecdotal evidence of the impact of the simulation was collected. Students were observed to react positively, displaying an increased understanding of the impacts of interruptions on $M A$, and an improved awareness of management strategies. Student feedback was collected for analysis using the written reflections. To obtain the academic 
teaching staff perspective, email interviews were conducted. Ethics approval was received from the relevant Ethics Committee.

\section{Creating the Scenario}

A case study was designed and presented in two, two hour sessions delivered one week apart. Knowledge and skills covered within the case study included; revision of respiratory physiology, oxygen therapy, administration of nebulised and metered dose medications, safe oral MA, case study specific pathophysiology, relevant pharmacology, clinical reasoning and communication. A creative learning experience that aimed to actively engage students by utilising simulation role-play was embedded within the clinical laboratory session during the second week of the case study.

Creation of the simulation experience was designed to reflect reality and incorporated both the Arthur, Levett-Jones and Kable (2010) framework, and a simulation scenario template created by Kelly (2013). Key skills addressed in line with the course curricula included; linking theory and practice, the use of clinical reasoning to manage the task of MA, prioritisation of care, communication skills, and review of medications specific to the case study.

The interruptions were chosen by reviewing literature for realistic and common causes of interruptions during MA (Biron, Lavoie-Tremblay \& Loiselle 2009; Palese et al. 2009; Relihan et al. 2010). Exposing undergraduate nurses to realistic and common interruptions in a safe simulated environment, aims to provide opportunities for students to recognise and prioritise interruptions that either do or do not require immediate attention (Biron, LavoieTremblay \& Loiselle 2009). 
All participants had previous exposure to both embedded simulation and dedicated simulation weeks. Previous involvement in large cohort simulations and "knowing what to expect' of the environment encourages students to willingly engage and be less fearful of the impending experience. Students have reported positive learning experiences highlighting the efficacy of this teaching tool (Rochester et al. 2012).

Students were supplied with information regarding the simulation within laboratory workbooks and were also briefed on the five available roles. Each role was designed to elicit critical thinking and clinical judgement. The roles included a registered nurse who was required to administer morning medications, a patient with a history of asthma, a confused patient, a second nurse who interrupts the administering nurse to have an intravenous fluid order checked, and an observer. To help the students orient themselves to the experience, they were also shown a short video clip with staff portraying the five roles. The vignette example did not provide solutions, but merely illustrated the roles and level of expected interruption. The classes were then divided into groups of five and the students selfselected the role they felt most comfortable with.

To increase engagement, props were utilised that could be easily donned and removed to signify the beginning and end of role immersion. These included: character lanyards with role identifiers and tips for role engagement, a wig and scarf for the confused patient, intravenous fluids and fluid order chart for the interrupting nurse, patient gown and wrist band for the asthmatic patient. Students were requested to wear their uniform to the laboratory session so that those taking on the role of administering nurse were able to embrace the role (Kesten et al. 2010; Prescott \& Garside 2009). 
Student centred debriefing is an essential part of the simulation experience (Neill \& Wotton 2011). Therefore, immediately following the simulation a short debrief was conducted for each group. In addition a full class debrief occurred at the end of the laboratory session to encourage consolidation of new concepts. A safe environment where students are free to reflect on identified areas for learning enhances the transfer of knowledge to practice (Arthur, Levett-Jones \& Kable 2010). The reflective process was extended by providing students with the opportunity to complete written reflections over subsequent weeks. Fostering further reflection allows time for deeper thinking around what has been learnt and how that might be able to transform practice.

Regular teaching staff facilitating the simulation fostered a comfortable and familiar learning environment. Academics involved in the simulation were briefed during an initial semester team meeting, via email with updates, and again on the day of the simulation. This ensured all participating academics had an understanding of how the simulation 'fit in' with the curricula and continuity could be assured. They were also supplied with information related to appropriate debriefing styles and methods. The majority of the academic staff members involved had previous simulation experience. Those new to simulation were offered additional support.

\section{Challenges}

To avoid overzealous character portrayal of the confused patient, the teaching staff briefed the student playing the confused patient so that they did not diminish the objective of the scenario. However, there were some instances where students began to dominate the scenario. This was managed by either calling a time out for discussion, or signalling the student in question to decrease the intensity of the role. 
Several members of the teaching team reported observing some male students resorting to physical restraint to control the confused patient. This was also managed by calling a time out to discuss options before returning to the simulation. Similarly it was reported that some students who had previous experience as enrolled nurses were requesting pharmacological restraint for the confused patient. These issues were discussed during the debrief that followed the scenario.

\section{DISCUSSION}

Administering medications requires multiple clinical judgments, professional vigilance and critical thinking (Cloete 2015, Eisenhauer, Hurley \& Dolan 2007). Understanding the external impacts on the safe delivery of medications and patient care is an integral part of the MA process (Cloete 2015, Page \& McKinney 2007), yet most current methods of teaching MA neglect to teach the critical thinking skills required to manage interruptions.

Biron et al. (2009) recognized that little is known about strategies used by nurses to manage interruptions, and that nurses need to learn to identify, prioritise and then manage interruptions at the undergraduate level. This is particularly important for beginning practitioners, as interruptions and distractions combined with inexperience, significantly increase the risk of errors and have been identified as the leading cause of errors in this cohort (Wolf, Hicks \& Serembus 2006). To facilitate the identification of interruption management strategies and individual areas of knowledge deficit, this role-play simulation experience acknowledged each of the steps in Tanners clinical judgement model, where complexity of the processes behind clinical reasoning and judgment are highlighted, accounting for external influences such as diversity in clinical situations, experiences and individual values (Tanner 2006). 
When planning learning experiences for undergraduate nurses, with limited experiential background from which to draw knowledge, guidance from academic staff and clinical experts is required (Benner, Tanner \& Chesla 2009). Ideally faculty are able to predict what students can reasonably expect to be exposed to, along with any obvious exceptions to those expectations. As students gain clinical exposure they build a repertoire of clinical experience. Sound clinical judgement is significantly enhanced by the experiential learning that occurs from exposure to clinical cases (Lasater 2007). This simulation was designed to build the repertoire of novice and beginning practitioner students by exposing them to a realistic clinical situation from which they could draw knowledge when in the actual clinical environment.

Some recent studies have utilised simulation technologies in an attempt to improve the MA skills of undergraduate nursing students resulting in positive learning experiences, and improved deductive reasoning and analysis (Ferguson, Delaney \& Hardy 2014; Harris et al. 2014). One study (Thomas, McIntosh \& Allen 2014), created simulated auditory distractions using headphones to develop student understanding of the relationship between distractions and medication error rates during MA. Identification of management strategies were discussed during the debriefing that followed the simulation, however the opportunity to extend the reflective process outside the simulation laboratory environment was not offered, nor was the chance for the students to immerse themselves in the role of the patient or the interrupter to feel what it was like from the perspective of others.

Taking on someone else's role in a simulation experience has been identified in the literature as facilitating insight into the situations of others (Rochman et al. 2012). However, high fidelity simulators are frequently used to portray the role of the patient, typically with 
teaching staff as the voice behind the patient. The role-play experience outlined in this paper differs from these experiences, and affords student participants the opportunity to fully immerse themselves in the role of the patient and their story of illness, including the associated emotional impacts, while improving understanding of the impacts of interruptions and identifying interruption management strategies.

Critical thinking begins and clinical judgements are made during simulation experiences, however, timely and appropriate debriefing must then follow to stimulate reflective learning (Ferguson, Delaney \& Hardy 2014; Harris et al. 2014; Rochman et al. 2012). Schon (1983) describes this as reflection 'on' action where one is able to spend time recalling an event in the pursuit of knowledge. This encourages increased student engagement, improves learning opportunities, and enriches insights into student thought processes. To extend the reflective learning process students were encouraged to complete written reflections independent of the debriefing process. Combining these experiences aligns with Kolb's experiential learning theory and Tanners model of clinical judgement (Kolb 1984; Tanner 2006).

Simulation, that employs varying levels of fidelity, has been used as a method for teaching undergraduate nursing at all levels of experience both locally and internationally for many years (Aggar \& Dawson 2014). It has been described as an educational strategy that utilises real world scenarios and environments to accomplish definite learning goals (Arthur, LevettJones \& Kable 2010). If students are engaged in carefully planned, clinically relevant simulation experiences appropriate to their stage of learning, then improved levels of understanding, self-efficacy, self-confidence, a feeling of being more ready for practice and 
transfer of new skills into the clinical environment are the likely results (Howard et al. 2011; Mould, White \& Gallagher 2011; Prescott \& Garside 2009).

Support is growing for well-planned simulation experiences that expose undergraduate student nurses to real world scenarios, including interruptions during MA (Aggar \& Dawson 2014; Raban \& Westbrook 2014). Deep learning can occur and new knowledge can be transferred into practice through transforming experiences such as the one presented in this paper (Kolb 1984). Encouraging undergraduate nurses to use critical thinking and reflect on the thought processes used to make sound clinical judgment, is essential to not only build reflective practitioners but also to provide safe care (Eisenhauer, Hurley \& Dolan 2007).

\section{Implications for research}

The simulation described in this paper has potential for building knowledge and expanding understanding. The written reflections will provide extensive qualitative data from which to draw an understanding of the impact of the experience from the student perspective. To enhance understanding of student written reflections, the addition of individual interviews will be beneficial. It would also be advantageous to determine impacts of the intervention on students following clinical practicum, including the impacts on medication error rates. The inclusion of documented medication error and near miss data collected during the simulation would provide quantitative data to review the impact of the student learning experience.

\section{CONCLUSION}

It is impossible to completely eliminate interruptions and distractions in the dynamic environment in which nurse's work. Current medication error prevention strategies revolve 
around eliminating interruptions and distractions during MA. Therefore it is incumbent on educators to ensure undergraduate nurses are able to manage interruptions as they occur. In order for student nurses to appropriately manage interruptions, and reduce errors, we must provide opportunities in which they are encouraged to discover the skills necessary to cultivate innate clinical reasoning that will lead to sound clinical judgements. Providing simulation of the real world in training should facilitate transfer of skills from theory to practice. 


\section{REFERENCE LIST}

Aggar, C.a. \& Dawson, S. 2014, 'Evaluation of student nurses'perception of preparedness for oral medication administration in clinical practice: A collaborative study. ', Nurse Education Today, vol. 34, pp. 899-903.

Anthony, K., Wiencek, C., Bauer, C., Daly, B. \& Anthony, M.K. 2010, 'No interruptions please: impact of a no interruption zone on medication safety in intensive care units [corrected] [published errata appear in CRIT CARE NURSE 2010 Aug;30(4):16, and Dec;30(6):16]', Critical Care Nurse, vol. 30, no. 3, pp. 21-30.

Arthur, C., Levett-Jones, T. \& Kable, A. 2010, 'Quality indicators for the design and implementation of simulation experiences: A Delphi Study.', Nurse Education Today.

Benner, P. 2001, From novice to expert: excellence and power in clinical nursing practice. Commemorative edition., Prentice Hall., New Jersey.

Benner, P., Tanner, C.A. \& Chesla, C. 2009, Expertise in nursing practice: caring, clinical judgment, and ethics. , 2nd. edn, Springer Publishing Company., New York.

Biron, A.D., Lavoie-Tremblay, M. \& Loiselle, C.G. 2009, 'Characteristics of work interruptions during medication administration', Journal of Nursing Scholarship, vol. 41, no. 4, pp. 330-6.

Cant, R.P. \& Cooper, S.J. 2011, 'The benefits of debriefing as formative feedback in nurse education.', Australian Journal of Advanced Nursing., vol. 29, no. 1, pp. 37-47.

Clark, A.P. \& Flanders, S. 2012, 'Interruptions and medication errors: part II', Clinical Nurse Specialist, vol. 26, no. 5, pp. 239-43.

Clinical Excellence Commission, C.A. \& Health, N.D.o. 2013, Clinical incident management in the NSW public health system 2010: July-December. Sydney.

Cloette, L. 2015, 'Reducing medication errors in nursing practice'. Cancer Nursing Practice, vol. 14, no. 1 , pp, 29-36.

Eisenhauer, L.A., Hurley, A.C. \& Dolan, N. 2007, 'Nurses' reported thinking during medication administration.', Journal of Nursing Scholarship, vol. 39, no. 1, pp. 82-7.

Ferguson, A., Delaney, B.a. \& Hardy, G. 2014, 'Teaching medication administration through innovative simulation.', Teaching \& Learning in Nursing, vol. 9, pp. 64-8.

Flanders, S. \& Clark, A.P. 2010, 'Interruptions and medication errors: part I', Clinical Nurse Specialist, vol. 24, no. 6, pp. 281-5.

Flynn, L., Liang, Y., Dickson, G.L., Xie, M. \& Suh, D.-C. 2012, 'Nurses' Practice Environments, Error Interception Practices, and Inpatient Medication Errors', Journal of Nursing Scholarship, vol. 44, no. 2, pp. 180-6.

Fore, A.M., Sculli, G.L., Albee, D. \& Neily, J. 2013, 'Improving patient safety using the sterile cockpit principle during medication administration: a collaborative, unit-based project', J Nurs Manag, vol. 21, no. 1, pp. 106-11.

Harris, M.A., Pittiglio, L., Newton, S.E.a. \& Moore, G. 2014, 'Using simulation to improve the medicaiton administration skills of undergraduate nursing students.', Nursing Education Perspectives, vol. 35, no. 1, pp. 26-9.

Howard, V.M., Englert, N., Kameg, K. \& Perozzi, K. 2011, 'Integration of simulation across the undergraduate curriculum: student and faculty perspectives', Clinical Simulation in Nursing, vol. 7, no. 1, pp. e1-e10.

Jeffries, P.R. 2005, 'A framework for designing, implementing, and evaluating: Simulations used as teaching strategies in nursing', Nursing Education Perspectives, vol. 26, no. 2, pp. 96-103.

Jenkins, P. \& Turick-Gibson, T. 1999, 'An exercise in critical thinking using role playing.', Nurse Educator, vol. 24, no. 6, pp. 11-4.

Jennings, B.M., Sandelowski, M. \& Mark, B. 2011, 'The nurse's medication day', Qualitative Health Research, vol. 21, no. 10, pp. 1441-51. 
Kelly, M. 2013, Simulation scenario template., University of Technology, Sydney, Faculty of Health. Kesten, K.S., Brown, H.F., Hurst, S. \& Briggs, L.A. 2010, 'Acute care for advanced practice nurses.', in W.M. Nehring \& F.R. Lashley (eds), High fidelity patient simulation in nursing education., Jones and Bartlett Publishers., Massachusetts.

Kohn, L.T., Corrigan, J.M. \& Donaldson, M.S. 2000, To err is human: building a safer health system., National Academy Press, Washington.

Kolb, D.A. 1984, 'Experiential Learning: experience as the source of learning and development.', PTR Prentice Hall., New Jersey.

Krautscheid, L.C., Orton, V.J., Chorpenning, L. \& Ryerson, R. 2011, 'Student nurse perceptions of effective medication administration education', International Journal of Nursing Education Scholarship, vol. 8, no. 1.

Lasater, K. 2007, 'Clinical judgment development: using simulation to create an assessment rubric.', Journal of Nursing Education., vol. 46, no. 11, pp. 496-503.

Lasater, K. 2009, 'Reflective journaling for clinical judgment development and evaluation.', Journal of Nursing Education., vol. 48, no. 1, pp. 40-4.

Mould, J., White, H. \& Gallagher, R. 2011, 'Evaluation of a critical care simulation series for undergraduate nursing students', Contemporary Nurse, vol. 38, no. 1-2, pp. 180-90.

Neill, M.A., and \& Wotton, K. 2011, 'High-fidelity simulation debriefing in nursing education: a literature review.', Clinical Simulation in Nursing, vol. 7, no. 5, pp. e161-e8.

Nielson, A., Stragnell, S. \& Jester, P. 2007, 'Guide for reflection using the clinical judgement model.', Journal of Nursing Education., vol. 46, no. 11, pp. 513-6.

Page, K. \& McKinney, A.A. 2007, 'Addressing medication errors - The role of undergraduate nurse education', Nurse Education Today, vol. 27, no. 3, pp. 219-24.

Palese, A., Sartor, A., Costaperaria, G. \& Bresadola, V. 2009, 'Interruptions during nurses' drug rounds in surgical wards: observational study', Journal of Nursing Management, vol. 17, no. 2, pp. 185-92.

Prescott, S. \& Garside, J. 2009, 'An evaluation of simulated clinical practice for adult branch students', Nursing Standard, vol. 23, no. 22, pp. 35-40.

Raban, M.Z. \& Westbrook, J.I. 2014, 'Are interventions to reduce interruptions and errors during medication administration effective?: a systematic reveiw.', BMJ Qual Saf, vol. 23, pp. 41421 .

Reid-Searl, K., Moxham, L. \& Happell, B. 2010, 'Enhancing patient safety: The importance of direct supervision for avoiding medication errors and near misses by undergraduate nursing students', International Journal of Nursing Practice, vol. 16, no. 3, pp. 225-32.

Relihan, E., O'Brien, V., O'Hara, S. \& Silke, B. 2010, 'The impact of a set of interventions to reduce interruptions and distractions to nurses during medication administration', Quality \& Safety in Health Care, vol. 19, no. 5, p. e52.

Rochester, S., Kelly, M., Disler, R., White, H., Forber, J. \& Matiuk, S. 2012, 'Providing simulation experiences for large cohorts of 1st year nursing students: Evaluating quality and impact', Collegian, vol. 19, no. 3, pp. 117-24.

Rochman, M.F., Aebersold, M., Tschannen, D. \& Cambridge, B. 2012, 'Interprofessional simulation on nurse interruptions', Journal of Nursing Care Quality, vol. 27, no. 3, pp. 277-81.

Schon, D.A. 1983, The reflective practitioner., Basic Books, New York.

Tanner, C.A. 2006, 'Thinking like a nurse. A research-based model of clinical judgement in nursing.', Journal of Nursing Education, vol. 45, no. 6, pp. 204-11.

Thomas, C.M., Mclntosh, C. E. \& Allen, R. 2014, 'Creating a distraction simulation for safe medicaiton administration.", Clinical Simulation in Nursing, vol 10, no.8, pp. 406-411.

Westbrook, J.I., Woods, A., Rob, M.I., Dunsmuir, W.T. \& Day, R.O. 2010, 'Association of interruptions with an increased risk and severity of medication administration errors', Archives of Internal Medicine, vol. 170, no. 8, pp. 683-90. 
Will, S.E. \& Weinschreider, J. 2012, 'Patient safety in human simulation.', in L. Wilson \& L. Rockstraw (eds), Human simulation for nursing and health professions., Springer Publishing Company., New York.

Wolf, Z.R., Hicks, R. \& Serembus, J.F. 2006, 'Characteristics of medication errors made by students during the administration phase: a descriptive study', Journal of Professional Nursing, vol. 22, no. 1, pp. 39-51.

Woodrow, R., Colbert, B. \& Smith, D.M. 2010, Essentials of pharmacology for health occupations. Sixth Edition., Cengage Learning, Delmar. 


\section{Diagram 1}

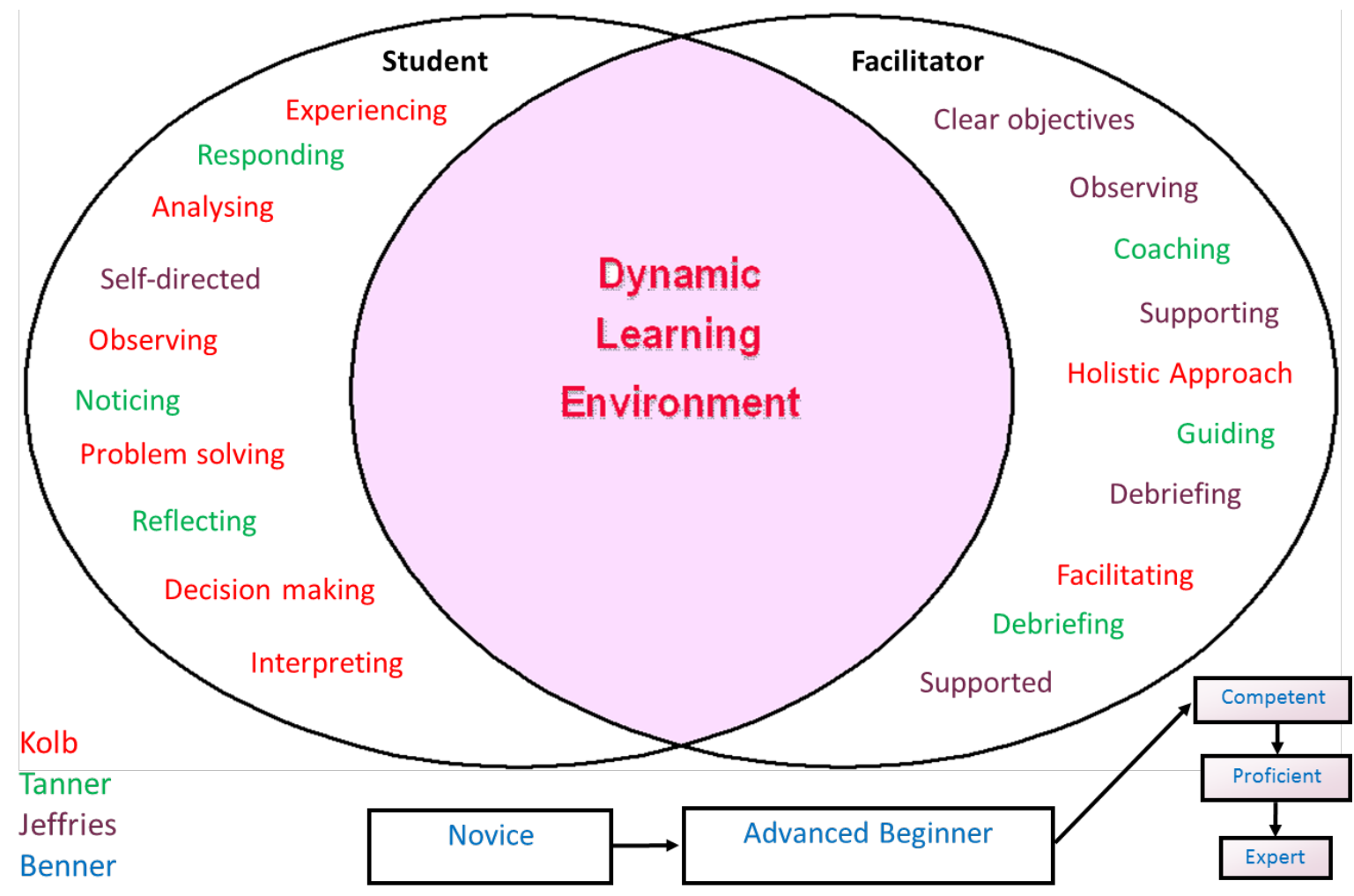


Table 1 - Quality indicator Statements (Arthur, Levett-Jones \& Kable 2010)

\begin{tabular}{|c|c|c|}
\hline Quality Indicator & Statement & Achieved by \\
\hline \multirow[t]{3}{*}{ Pedagogical principles } & $\begin{array}{l}\text { 1. The simulation experience is } \\
\text { aligned with curriculum and } \\
\text { course objectives. }\end{array}$ & $\begin{array}{l}\text { 1. The Faculty developed a program } \\
\text { where "enquiry-based, scenario } \\
\text { based and solution focused } \\
\text { approaches" p } 119 \text { (Rochester et } \\
\text { al. 2012), heavily utilise simulation } \\
\text { as a learning tool. }\end{array}$ \\
\hline & $\begin{array}{l}\text { 2. Simulation experiences } \\
\text { increasing in intensity are } \\
\text { integrated throughout the } \\
\text { course. }\end{array}$ & $\begin{array}{l}\text { 2. All students have been exposed to } \\
\text { large cohort dedicated sim weeks } \\
\text { in their first year of study along } \\
\text { with more complex scenario based } \\
\text { embedded simulation experiences } \\
\text { within clinical laboratory classes. }\end{array}$ \\
\hline & $\begin{array}{l}\text { 3. Learning objectives guide the } \\
\text { design of the simulation. }\end{array}$ & $\begin{array}{l}\text { 3. The learning objectives guiding this } \\
\text { experience included: clinical } \\
\text { reasoning when interrupted during } \\
\text { the task of medication } \\
\text { administration, linking theory and } \\
\text { practice, prioritisation of care, } \\
\text { communication skills, and review } \\
\text { of medications specific to the case } \\
\text { study. }\end{array}$ \\
\hline \multirow[t]{3}{*}{ Fidelity } & $\begin{array}{l}\text { 1. Range of methods used align } \\
\text { with learning objectives }\end{array}$ & $\begin{array}{l}\text { 1. Role play was used in this } \\
\text { simulation experience to increase } \\
\text { student immersion. }\end{array}$ \\
\hline & $\begin{array}{l}\text { 2. Environmental fidelity is } \\
\text { appropriate to the simulation } \\
\text { experience }\end{array}$ & $\begin{array}{l}\text { 2. The learning space was set up as if } \\
\text { in a ward environment, and } \\
\text { included the availability of props } \\
\text { for each role. }\end{array}$ \\
\hline & $\begin{array}{l}\text { 3. Clinical equipment used is } \\
\text { applicable to the scenario } \\
\text { and enhances realism }\end{array}$ & $\begin{array}{l}\text { 3. Medication trolley, IV fluids and } \\
\text { appropriate charts were supplied } \\
\text { for use. }\end{array}$ \\
\hline $\begin{array}{lll}\text { Student } & \text { preparation } & \text { and } \\
\text { orientation } & & \end{array}$ & $\begin{array}{l}\text { 1. There is an introduction to } \\
\text { learning objectives, timing } \\
\text { and process of the } \\
\text { experience, the environment } \\
\text { in which they will be } \\
\text { immersed, and available } \\
\text { equipment. }\end{array}$ & $\begin{array}{l}\text { 1. Students were provided with } \\
\text { information regarding the } \\
\text { simulation in their course } \\
\text { workbooks as well as by } \\
\text { information handouts and verbal } \\
\text { orientation at the time of the } \\
\text { simulation. }\end{array}$ \\
\hline Staff preparation and training & $\begin{array}{l}\text { 1. Staff designing and/or } \\
\text { involved in the simulation are } \\
\text { provided with appropriate } \\
\text { training }\end{array}$ & $\begin{array}{l}\text { 1. All staff involved in the simulation } \\
\text { attended course content briefing } \\
\text { at the beginning of the semester } \\
\text { along with regular email updates } \\
\text { and information and were also } \\
\text { briefed individually prior to the } \\
\text { simulation experience. }\end{array}$ \\
\hline
\end{tabular}




\begin{tabular}{|c|c|c|c|}
\hline & $\begin{array}{l}\text { 2. Staff designing the simulation } \\
\text { are familiar with the } \\
\text { curriculum and course } \\
\text { objectives }\end{array}$ & 2. & $\begin{array}{l}\text { One of the staff members involved } \\
\text { in designing the simulation } \\
\text { included the subject co-ordinator } \\
\text { ensuring alignment with } \\
\text { curriculum and course objectives. }\end{array}$ \\
\hline Debriefing & $\begin{array}{l}\text { 1. Structured debriefing is } \\
\text { facilitated directly following } \\
\text { the simulation which allows } \\
\text { for student reflection, self- } \\
\text { evaluation and feedback of } \\
\text { the experience. }\end{array}$ & 1. & $\begin{array}{l}\text { The students were provided with a } \\
\text { debriefing experience following } \\
\text { each cycle of the simulation and } \\
\text { then again as a large group at the } \\
\text { end of the class. Suggested } \\
\text { debriefing questions were } \\
\text { provided to the facilitators that } \\
\text { encouraged student reflection on } \\
\text { how they felt 'in role', as a part of } \\
\text { the team, identifying clinical } \\
\text { reasoning to explain how they } \\
\text { interacted/reacted to the } \\
\text { experience and communication } \\
\text { issues that arose. }\end{array}$ \\
\hline
\end{tabular}

